\title{
Correlation of Electric Cardiometry and Continuous Thermodilution Cardiac Output Monitoring Systems
}

\author{
Vishwas Malik' ${ }^{1}$, Arun Subramanian1*, Sandeep Chauhan1, Milind Hote ${ }^{2}$ \\ ${ }^{1}$ Department of Cardiac Anesthesiology, All India Institute of Medical Sciences, New Delhi, India \\ ${ }^{2}$ Department of Cardiothoracic and Vascular Surgery, All India Institute of Medical Sciences, New Delhi, India \\ Email: ${ }^{*}$ mkknso@gmail.com
}

Received 1 May 2014; revised 1 June 2014; accepted 1 July 2014

Copyright (C) 2014 by author and Scientific Research Publishing Inc.

This work is licensed under the Creative Commons Attribution International License (CC BY). http://creativecommons.org/licenses/by/4.0/

(c) (i) Open Access

\begin{abstract}
Purpose: Impedance Cardiography (ICG) with its drawbacks to reliably estimate cardiac output (CO) when compared to reference methods has led to the development of a novel technique called Electrical Cardiometry (EC). The purpose of this study was to compare EC-CO with the Continuous CO (CCO) derived from Pulmonary Artery Catheter (PAC). Methods: 60 patients scheduled to undergo coronary artery surgery necessitating the placement of PAC were studied in the operating room. Standard ECG electrodes were used for EC-CO measurements. Simultaneous CO measurement from EC and PAC was done at three predefined time points and were correlated. Results: A significant high correlation was found between the EC-CO and $\mathrm{CCO}$ at the three time points. Bland and Altman analysis revealed a bias of $0.08 \mathrm{~L} / \mathrm{min}$, a precision of $0.15 \mathrm{~L} / \mathrm{min}$, with a narrow limit of agreement ( -0.13 to $0.28 \mathrm{~L} / \mathrm{min})$. The percentage error between the methods was $3.59 \%$. Conclusion: The agreement between EC-CO and $\mathrm{CCO}$ is clinically acceptable and these two techniques can be used interchangeably. Mediastinal opening has no effect on the correlation between these two modalities.
\end{abstract}

\section{Keywords}

Pulmonary Artery Catheter, Electrical Cardiometry, Cardiac Output, Thermodilution

\section{Introduction}

In clinical anesthesia and critical care medicine, it is essential to measure the cardiac output (CO) for clinical

\footnotetext{
"Corresponding author.
}

How to cite this paper: Malik, V., Subramanian, A., Chauhan, S. and Hote, M. (2014) Correlation of Electric Cardiometry and Continuous Thermodilution Cardiac Output Monitoring Systems. World Journal of Cardiovascular Surgery, 4, 101-108. 
decision making and research purposes. This has led to the development of safe, simple and non-invasive techniques for the assessment of the same [1]. The uncertain risk-benefit ratio of pulmonary artery catheterization has led to the development of multiple minimally invasive and non-invasive methods of determination of cardiac output [2] [3].

Continuous CO (CCO) measurement by pulmonary artery catheter (PAC) utilizes electrical impulses to generate heat in the coils mounted on PAC [4]. The heat signals generated result in changes in blood temperature, which are measured by a thermistor. A computer algorithm then analyzes these patterns of blood temperature to calculate CO over 3 - 4 minutes.

Impedance Cardiography (ICG) which was introduced nearly 45 years ago has been studied extensively for the determination of cardiac output. ICG has been compared with thermodilution techniques in the clinical scenarios for the estimation of cardiac output. But the results have either been disappointing or inconclusive [5]-[7]. The reasons could be the physical-physiological basis of ICG and the differences in its methodology [8] or the thermodilution technique itself [9].

Electrical Cardiometry (EC) is a recently developed technology to measure the cardiac output. Both ICG and EC derive CO from measurements of Thoracic Electrical Bioimpedance (TEB). TEB is the least invasive method of measuring CO. As proposed by Kubicek [10], TEB is based on the theory that the thorax is a cylinder that is perfused with a fluid (blood) of a specific resistivity. TEB is the electrical resistance to high frequency low amplitude current that is transmitted from electrodes placed on the upper and lower thorax. The resultant value is indirectly proportional to the volume of thoracic fluids such that increasing fluid in the thorax results in less TEB. Therefore, the inverse of TEB, and thus changes in CO, are reflected as a change in total bioimpedance or fluid conductivity. Originally, the Kubicek equation was used to calculate the CO from TEB which was later modified by Bernstein [10] [11] to account for the non-cylindrical shape of the chest, which might result in an erroneous determination of the CO. While ICG attributes the steep increase in the conductivity waveform to a volumetric expansion of the aorta during systole, EC contributes the increase in conductivity to the orientation change of the RBCs to determine the velocity of the blood flow. EC analyzes the maximum rate of change of TEB as the ohmic equivalent of mean aortic blood flow acceleration [12]. Thus, the algorithm and evident accuracy of EC compared to ICG is what separates the two methods. EC is likely to provide more accurate information on CO, independent of the volume of the surrounding tissue which is highly variable and might interfere with the results of ICG.

Though CO using EC has been studied in the clinical settings and compared with the intermittent thermodilution technique (ITD), the correlations of EC with CCO have not been done in the clinical settings. Therefore, in the present study we compared the EC with CCO during coronary artery bypass grafting (CABG) using cardiopulmonary bypass (CPB). In the current study we employed CCO instead of ITD because ITD needs the temperature of the injectate and the speed of injection to be maintained constant throughout the course of the study.

\section{Methods}

After obtaining institutional ethics committee approval and written informed consent, 60 adult patients scheduled to undergo CABG were enrolled in this study. The study was performed from July 2013 to December 2013. Patients with significant valvular heart disease, atrial fibrillation, pacemakers, cardiogenic shock, bundle branch blocks, cardiac masses, intracardiac shunts, chronic obstructive pulmonary disease and body mass index > 25 were excluded from this study. Anesthetic management was at the discretion of the chief anesthetist. Post intubation, a balloon tipped, flow-directed CCO-PAC (7.5 F, Edwards Lifesciences, Irvine, CA) was placed via the right internal jugular vein up to the wedge position and the correct position was confirmed by pressure tracings as well as transesophageal echocardiography. The PAC was connected to Vigilance II monitor (Edwards Lifesciences, Irvine, CA) which determines the CCO after filling in the patient demographics. The pressure transducer was zeroed at the mid axillary line. Readings from PAC were taken in the stat mode. Four sensors were applied- first: approx $5 \mathrm{~cm}$ above left base of the neck, second on the left base of neck, third on the lower left thorax at level of xiphoid and the fourth one on the lower left thorax approx $5 \mathrm{cms}$ below the $3^{\text {rd }}$ electrode at the level of anterior axillary line. The Electrical cardiometry monitor (Electrical Cardiometry monitor, ICON Cardiotronics, Inc., La Jolla, CA 92307; Osypka Medical GmbH, Berlin, Germany) was connected to the sensor cable and the patient data were fed. The ICON monitor incorporates an algorithm which transforms the ohmic 
equivalent of mean aortic blood flow acceleration into an equivalent of mean aortic blood flow velocity [12]. The ICON device emits a high frequency $(50 \mathrm{kHz})$ and low-amperage $(2 \mathrm{~mA})$ alternating electrical current of constant amplitude via a pair of surface electrodes across the left side of the thorax. The voltage drop due to the current application is registered together via a second pair of sensing electrodes which were located at the left side of the neck and the left side of the thorax at the level of the xiphoid process, inside the current electrodes. Prior to opening of the aortic valve, the red blood cells (erythrocytes) assume a random orientation (there is no blood flow in the aorta). When the electric current is applied from the outer electrodes, the current must circumference these red blood cells, therefore resulting in a higher voltage measurement, and thus, a lower conductivity. Shortly after aortic valve opening, the pulsatile blood flow forces the red blood cells to align in parallel with the blood flow. When the electric current is then applied, it is able to easily pass the red blood cells in the aorta resulting in a lower voltage, and thus, a higher conductivity. The change from random orientation to alignment of red blood cells upon opening of aortic valve generates a characteristic steep increase of conductivity or dZ (t) (corresponding to a steep decrease of impedance)—beat to beat.

\section{Data Recording}

Cardiac output data couplets were obtained, one from electric cardiometry site and second from the PAC at same point of time, at three predefined time intervals by two different operators: (1) T1, 10 min after anaesthetic induction when arterial cannulas and PAC were in situ and electric cardiometry electrodes had been placed but prior to sternotomy and (2) T2, at the time of internal mammary artery dissection and (3) T3, after sternal closure None of the measurements were recorded during arrhythmias or directly after vasopressor bolus or modification. The results were analyzed in a comparison of cardiac outputs at the three time points between the Electrical Cardiometry monitor with the thermodilution technique. Both operators were blinded for the $\mathrm{CO}$ values achieved by either technique.

\section{Statistical Analysis}

All results were analyzed by SPSS 16.0 for Microsoft windows. It was estimated that to recognize a clinically significant CO difference of $300 \mathrm{ml} / \mathrm{min}$ between the two methods with a power of 0.80 , at least 120 paired samples be compared. This power calculation included adjustment for multiple measurements on each patient. Agreement between CCO and EC-CO was evaluated in the following ways. First, the differences between the paired $\mathrm{CO}$ values were plotted against the average $\mathrm{CO}$ values of both measurements. This statistical method was recommended by Bland and Altman [13] for evaluation studies. Bias was calculated as the mean difference between CCO and EC-CO and precision as $\pm 1.96 \mathrm{SD}$ (95\% confidence intervals) of the differences between CCO and EC-CO. Limits of agreement were calculated arbitrarily as \pm 2 SD of biases. The percentage error $(100 \times$ precision/mean CO) was calculated according to Critchley and Critchley [14] for comparison of CO values. A mean percentage error less than $30 \%$ was defined to indicate clinical useful reliability of ICON monitor. Secondly, repeated measures analysis was performed followed by post-hoc comparison by Bon-Ferroni analysis, for the data couplets taken at three different time intervals. Thirdly, correlation between these values was evaluated by calculating the Pearson correlation coefficient (r) and applying a linear regression model of the EV-CO on CCO-CO. A p-value $<0.05$ was considered statistically significant.

\section{Results}

Sixty patients were enrolled in the current study. No patient was omitted from the analysis due to any technical or procedure related complications. The demographic and hemodynamic profiles of the patients are given in the table (Table 1). All the patients had an uneventful induction and subsequent coronary artery surgery.

A total of 180 pairs of CO measurements were taken with the PAC and ICON in the operating room. The following table analyzes the CO taken at different time intervals along with the average CO by both the methods (Table 2). The average CO derived from both the methods were $4.13 \pm 0.80 \mathrm{~L} / \mathrm{min}$ and $4.20 \pm 0.79 \mathrm{~L} / \mathrm{min}$ respectively.

The mean difference (bias) between CCO and EC-CO was $0.08 \mathrm{~L} / \mathrm{min}$ with a precision of $0.15 \mathrm{~L} / \mathrm{min}$. The limits of agreement are defined as bias $\pm 1.96 \mathrm{SD}$ and thereby the lower limits were $-0.13 \mathrm{~L} / \mathrm{min}$ and the upper limits were $0.28 \mathrm{~L} / \mathrm{min}$. The percentage error between the methods was $3.59 \%$ (Figure 1). Four values fell outside 
Table 1. Patient characteristics and hemodynamic measurements in 60 patients; Data are mean (range) or mean (SD).

\begin{tabular}{|c|c|}
\hline Age (years) & $54.6(41-67)$ \\
\hline Height $(\mathrm{cm})$ & $162(10)$ \\
\hline No. of participants & 60 \\
\hline Males & 34 \\
\hline Females & 26 \\
\hline Weight (kg) & $78(8.5)$ \\
\hline Left Ventricular Ejection Fraction (\%) & $49.8(9.6)$ \\
\hline Heart Rate (beats/min) & $63(14)$ \\
\hline Mean Arterial Pressure (mm Hg) & $86(15.1)$ \\
\hline Central Venous Pressure (mm Hg) & $8(4)$ \\
\hline Pulmonary Artery Pressure (mm Hg) & $23(11)$ \\
\hline Pulmonary Capillary Wedge Pressure (mm Hg) & $17(9)$ \\
\hline
\end{tabular}

Table 2. Comparison of CCO and EC-CO at various time points by Pearson Correlation (r).

\begin{tabular}{cccccc}
\hline Time point & CCO $(\mathrm{L} / \mathrm{min})$ Mean \pm SD & ECCO $(\mathrm{L} / \mathrm{min})$ Mean \pm SD & Correlation $(\mathrm{r})$ & $\mathrm{p}$ value & Bias \\
\hline T1 & $3.81 \pm 0.90$ & $3.89 \pm 0.88$ & 0.982 & $<0.01$ & 0.08 \\
T2 & $4.03 \pm 0.80^{\mathrm{a}}$ & $4.09 \pm 0.81^{\mathrm{a}}$ & 0.988 & $<0.01$ & 0.06 \\
T3 & $4.55 \pm 0.67^{\mathrm{a}}$ & $4.64 \pm 0.69^{\mathrm{a}}$ & 0.978 & $<0.01$ & 0.09 \\
Average & $4.13 \pm 0.80$ & $4.20 \pm 0.79$ & 0.983 & $<0.01$ & 0.07 \\
\hline
\end{tabular}

${ }^{\mathrm{a}}$ Value significantly different from previous time point within the group $(\mathrm{p}<0.04)$ by repeated measures analysis.

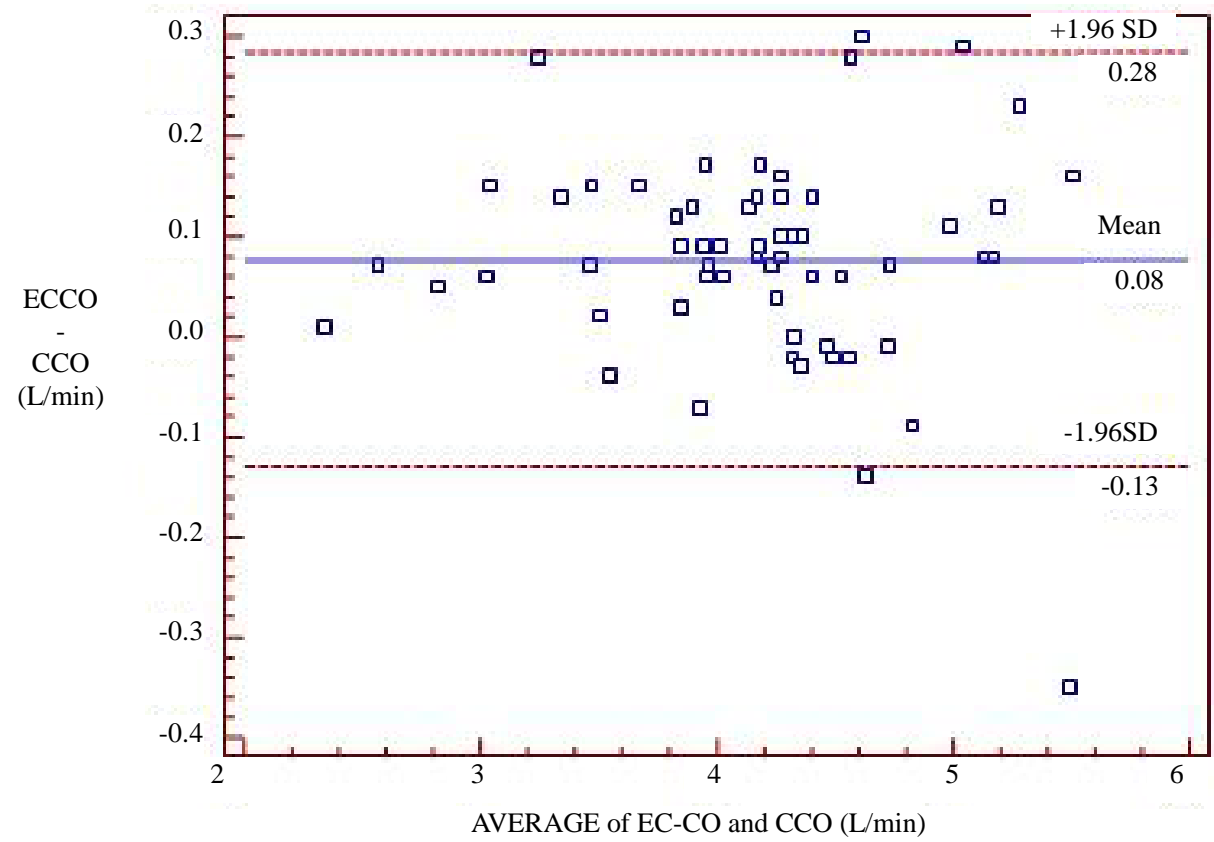

Figure 1. Bland Altman Analysis of EC-CO and CCO at all time points. X-axis-mean CO from EC and CCO [(CCO + EC-CO) $] / 2$ and Y-axis-CO difference (CCO-ECCO). Correlation $=0.978$ $(\mathrm{p}<0.01)$, bias $=0.08 \mathrm{~L} / \mathrm{min}$, precision $=0.15 \mathrm{~L} / \mathrm{min}$ and percent error $=3.59 \%$. 
the limits of agreement. Analysis for repeated measurements from both PAC and EC were also performed which yielded a p value $<0.04$ for both EC-CO and PAC-CO. The trend in CO using both the techniques is illustrated in Figure 2. The high correlation between EC and PAC was noted at the three time points by linear regression analysis (Figure 3).

\section{Discussion}

EC-CO and CCO were compared intra-operatively in this study at various points in time. They correlated significantly at all points of time during the course of the study. The bias was small; the upper and lower limits of agreement were very narrow with an acceptable percentage of error.

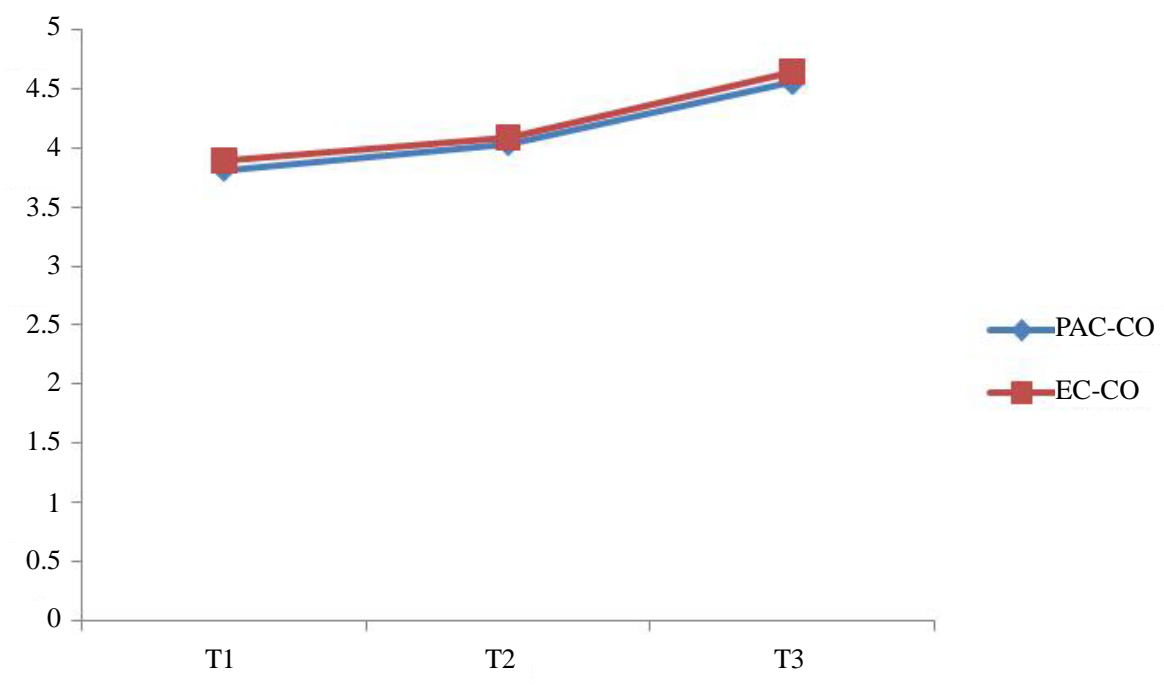

Figure 2. The trend analysis of CO derived from PAC and EC at three different time points. $\mathrm{X}$-axis: Time points (T1, T2, T3) and Y-axis: Cardiac output measurements.

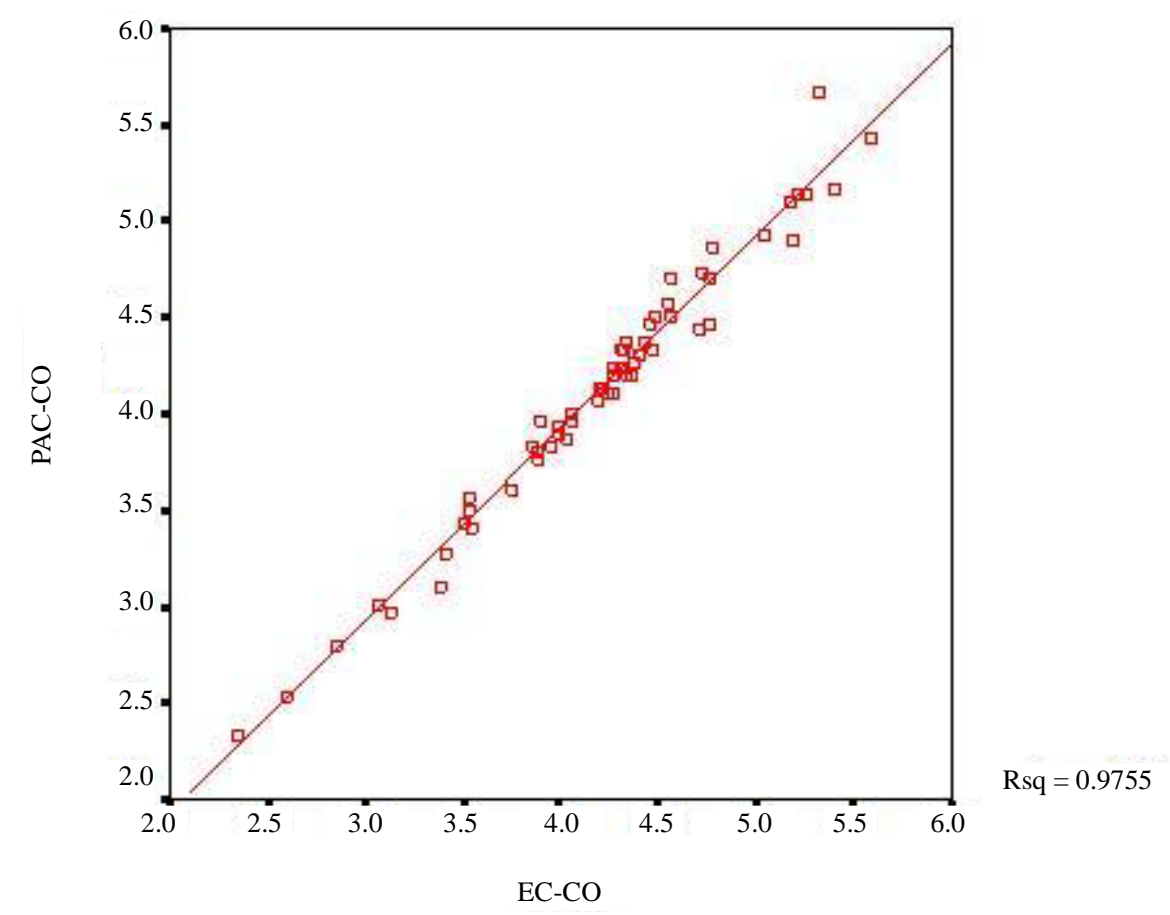

Figure 3. Linear regression analysis of CO measurements using PAC and EC ( $n=60)$. 
Critchley and colleagues [14] reported an overall mean CO of $4.8 \mathrm{~L} /$ min during their study using thoracic bioimpedance. They had compared it with intermittent thermodilution. The overall bias from these studies was $0.6 \mathrm{~L} / \mathrm{min}$, and the overall limits of agreement were $\pm 1.7 \mathrm{~L} / \mathrm{min}$. The percentage error for studies using the bioimpedance method was $37 \%$. The authors provided criteria which allowed quantification of acceptable limits of agreement between two CO measurement techniques. They assumed an inherent error of $\pm 20 \%$ for measurement of CO. The error in the thermodilution technique was $22 \%$ for single measurements [15] [16]. By combining the errors of both the test and the reference, Critchley and colleagues demonstrated that a mean percentage error of $\pm 30 \%$ between two different methods is clinically acceptable if the inherent errors in both techniques are similar to the expected error in thermodilution CO measurements. So, we can infer the two techniques can be interchanged for the measurement of CO.

The methodology used to calculate CO from TEB has evolved significantly recently [3]. TEB is affected by tissue fluid volume and changes in the volume of pulmonary and venous blood induced by respiration. This "noise" must be filtered out from the desired changes in volumetric blood flow of the aorta. Any alteration in the position or contact of the electrodes will thus affect these measurements. Newer generation devices, overcome some of the initial limitations of the first generation TEB devices by having 1) faster signal processing, 2) better signal filtering, 3) improved ECG triggering, 4) improved arrhythmia detection, and 5) respiratory filtering. In an intra-operative study of patients undergoing CABG surgery, TEB did well initially in determining CO when compared with PAC, however, during the immediate postoperative period, the correlation as measured by Bland-Altman analysis was not as robust [17]. A newer monitor, the Aesculon (Aesculon Electrical Velocimetry, Osypka Medical GmbH, Berlin, Germany) uses electrical velocimetry, which interprets the maximum rate of change of TEB to calculate CO. This monitor has shown some promise in postoperative cardiac surgical patients (both hemodynamically stable and unstable) [18]. Lazar et al. [19] demonstrated a good correlation between Aesculon and thermodilution in post surgical patients. In contrast, Heringlake et al. in their study comparing the Aesculon device with PAC in the intraoperative and post operative settings found a weak correlation which they attributed to the electrical artifacts in the impedance tracings [20]. Similar reports were published by Tomaske et al. and Petter et al. [21] [22] in patients with structural heart diseases and pulmonary hypertension respectively. In the present study the Electrical Cardiometry monitor (ICON Cardiotronics, Inc., La Jolla, CA 92307; Osypka Medical GmbH, Berlin, Germany) which works on the Bernstein modification of Kubicek's equation was tested with the PAC derived CCO. Our results are somewhat similar to the works done at other hospitals by different investigators [23]-[27]. Unlike us, they had compared the devices in the post-cardiac surgical patients. The present study was different in that it was carried out solely in the operating room. Moreover continuous thermodilution was used in our study rather than the ITD. Our observations were akin to Spiess et al. [17] who reported that mediastinal opening and cardiopulmonary bypass had minimal effect on the correlation between the two technologies. Van der Meer et al. [28] showed that TEB correlated weakly with PAC derived CO in obese patients. So in the present study we avoided obese patients as this patho-physiological variable can limit the validity of TEB. We also excluded patients with coexisting structural heart diseases to avoid the erroneous readings provided by PAC. Likewise, we did not record any data during the use of diathermy to avoid false measurements by ICON.

Thermodilution technique is invasive and has been criticized for its cost and risk-benefit ratio [2]. This has led to the continuing search for non-invasive devices for the measurement of CO. ICG which has come up in the last four decades was one such method. But the performance of ICG was found to be weakly correlating with the standard techniques. Interestingly, Kaukinen and colleagues [29] concluded that agreement between whole-body ICG and bolus thermodilution is slightly inferior to that between the bolus and continuous thermodilution methods but not to the extent that it hampers the use of ICG for the continuous monitoring of CO. Electrical Cardiometry (ICON) is likely to give more accurate results than ICG in the clinical settings. Noonan et al. in their investigation on univentricular hearts concluded that ICON provides a novel technique for continuous non-invasive cardiac output monitoring [30]. But this study was carried out exclusively in the cardiac catheterization laboratory. Moreover ICON was not compared to any of the standard cardiac output monitoring device. Sufficient data regarding the usage of ICON in the perioperative settings is lacking. Further studies with this novel device might give us a better idea on its performance.

To summarize, the ICON, working on the principle of electrical cardiometry (a new ICG algorithm) can provide $\mathrm{CO}$ quite reliably. It can be interchanged with the CCO for beat-beat estimation of cardiac output. 


\section{Limitations}

Our study had a couple of limitations. The reference method used in our study was a CCO which is not the gold standard for the measurement of CO. Secondly, we could have taken the readings at more frequent intervals but were prevented from doing so by the hemodynamic disturbances during surgical manipulations and the use of diathermy (which affected the impedance of the sensors) that occurred at these time points.

\section{Financial Disclosure}

The funds for CCO-PAC were procured from the Institute Research Grant sanctioned by the All India Institute of Medical Sciences, New Delhi, India.

\section{Conflict of Interest}

Nil.

\section{References}

[1] Colucci, W.S. and Braunwald, E. (1997) Pathophysiology of Heart Failure. In: Braunwald, E., Ed., Heart Disease, A Textbook of Cardiovascular Medicine, WB Saunders, Philadelphia, 394-420.

[2] Sandham, J.D., Hull, R.D., Brant, R.F., Knox, L., Pineo, G.F., Doig, C.J., et al. (2003) A Randomized, Controlled Trial of the Use of Pulmonary-Artery Catheters in High-Risk Surgical Patients. The New England Journal of Medicine, 348, 5-14. http://dx.doi.org/10.1056/NEJMoa021108

[3] Moshkovitz, Y., Kaluski, E., Milo, O., Vered, Z. and Cotter, G. (2004) Recent Developments in Cardiac Output Determination by Bioimpedance: Comparison with Invasive Cardiac Output and Potential Cardiovascular Applications. Current Opinion in Cardiology, 19, 229-237. http://dx.doi.org/10.1097/00001573-200405000-00008

[4] Mathew, L. and Singh, R.K. (2006) Swan-Ganz Catheter in Hemodynamic Monitoring. Journal of Anaesthesiology Clinical Pharmacology, 22, 335-345.

[5] Fuller, H.D. (1992) The Validity of Cardiac Output Measurement by Thoracic Impedance: A Meta Analysis. Clinical \& Investigative Medicine, 15, 103-112.

[6] Jensen, L., Yakimets, J. and Teo, K.K. (1995) A Review of Impedance Cardiography. Heart Lung, 24, 183-193. http://dx.doi.org/10.1016/S0147-9563(05)80036-6

[7] Marik, P., Pendelton, J. and Smith, R. (1997) A Comparison of Hemodynamic Parameters Derived from Transthoracic Electrical Bioimpedance with Those Parameters Obtained by Thermodilution and Ventricular Angiography. Chest, 25, 1545-1550.

[8] Raaijmakers, E., Faes, T.J., Scholten, R.J., Goovaerts, H.G. and Heethaar, R.M. (1999) A Meta-Analysis of Published Studies Concerning the Validity of Thoracic Impedance Cardiography. Annals of the New York Academy of Sciences, 873, 121-127. http://dx.doi.org/10.1111/j.1749-6632.1999.tb09458.x

[9] Kubo, S.H., Burchenal, J.E. and Cody, R.J. (1987) Comparison of Direct Fick and Thermodilution Cardiac Output Techniques at High Flow Rates. The American Journal of Cardiology, 59, 384-386. http://dx.doi.org/10.1016/0002-9149(87)90829-0

[10] Kubicek, W.G., Kottke, J., Ramos, M.U., Patterson, R.P., Witsoe, D.A., Labree, J.W., et al. (1974) The Minnesota Impedance Cardiograph: Theory and Applications. BioMedical Engineering, 9, 410-416.

[11] Bernstein, D.P. (1986) A New Stroke Volume Equation for Thoracic Bioimpedance: Theory and Rationale. Critical Care Medicine, 14, 904-909. http://dx.doi.org/10.1097/00003246-198610000-00017

[12] Bernstein, D.P. and Osypka, M.J. (2003) Apparatus and Method for Determining an Approximation of the Stroke Volume and the Cardiac Output of the Heart. US Patent 6,511,438 B2.

[13] Bland, J. and Altman, D.G. (1986) Statistical Methods for Assessing Agreement between Two Methods of Clinical Measurement. Lancet, 327, 307-310. http://dx.doi.org/10.1016/S0140-6736(86)90837-8

[14] Critchley, L.A.H. and Critchley, J.A.J.H. (1999) A Meta-Analysis of Studies Using Bias and Precision Statistics to Compare Cardiac Output Measurement Techniques. Journal of Clinical Monitoring and Computing, 15, 85-91. http://dx.doi.org/10.1023/A:1009982611386

[15] Mackenzie, J.D., Haites, N.E. and Rawles, J.M. (1986) Method of Assessing the Reproducibility of Blood Flow Measurement: Factors Influencing the Performance of Thermodilution Cardiac Output Computers. Heart, 55, 14-24. http://dx.doi.org/10.1136/hrt.55.1.14 
[16] Stetz, C.W., Miller, R.G., Kelly, G.E. and Raffin, T.A. (1982) Reliability of the Thermodilution Method in the Determination of Cardiac Output in Clinical Practice. American Review of Respiratory Disease, 126, 1001-1004.

[17] Spiess, B.D., Patel, M.A., Soltow, L.O. and Wright, I.H. (2001) Comparison of Bioimpedance versus Thermodilution Cardiac Output during Cardiac Surgery: Evaluation of a Second-Generation BIOIMPEDANCE device. Journal of Cardiothoracic and Vascular Anesthesia, 15, 567-573. http://dx.doi.org/10.1053/jcan.2001.26533

[18] Suttner, S., Schollhorn, T., Boldt, J., Mayer, J., Rohm, K.D., Lang, K. and Piper, S.N. (2006) Noninvasive Assessment of Cardiac Output Using Thoracic Electrical Bioimpedance in Hemodynamically Stable and Unstable Patients after Cardiac Surgery: A Comparison with PULMONARY artery Thermodilution. Intensive Care Medicine, 32, 2053-2058. http://dx.doi.org/10.1007/s00134-006-0409-x

[19] Lazar, S., Jerusalem, Z., Rube, J., Kolosky, C., Gojka, M., Dalal, B., et al. (2012) Electrical Cardiometry Compares Favorably with Thermodilution for Post Operative Hemodynamic Monitoring. Critical Care Medicine, 40, 386.

[20] Heringlake, M., Handke, U., Hanke, T., Eberhardt, F., Schumacher, J., Gehring, H. and Heinze, H. (2007) Lack of Agreement between Thermodilution and Electrical Velocimetry Cardiac Output Measurements. Intensive Care Medicine, 33, 2168-2172. http://dx.doi.org/10.1007/s00134-007-0828-3

[21] Tomaske, M., Knirsch, W., Krestchmar, O., Woitzek, K., Balmer, C., Schmitz, A., et al. (2008) Cardiac Output Measurement in Children: Comparison of Aesculon Cardiac Ouput Monitor and Thermodilution. British Journal of Anaesthesia, 100, 517-520. http://dx.doi.org/10.1093/bja/aen024

[22] Petter, H., Erik, A., Bjorn, E. and Goran, R. (2011) Measurement of Cardiac Output with Non-Invasive Aesculon Impedance versus Thermodilution. Clinical Physiology and Functional Imaging, 31, 39-47. http://dx.doi.org/10.1111/j.1475-097X.2010.00977.x

[23] Sageman, W.S., Riffenburg, R.H. and Spiess, B.D. (2002) Equivalance of Bioimpedece and Thermodilution in Measuring Cardiac Index after Cardiac Surgery. Journal of Cardiothoracic and Vascular Anesthesia, 16, 8-14. http://dx.doi.org/10.1053/jcan.2002.29635

[24] Gujjar, A.R., Muralidhar, K., Banakal, S., Gupta, R., Sathyaprabha, T.N. and Jairaj, P.S. (2008) Non Invasive Cardiac Output by Trans Thoracic Electrical Bioimpedance in Post Cardiac Surgery Patients: Comparison with Thermodilution Method. Journal of Clinical Monitoring and Computing, 22, 175-180. http://dx.doi.org/10.1007/s10877-008-9119-y

[25] Chakravarthy, M., Rajeev, S. and Jawali, V. (2009) Cardiac Index Measurement by Invasive, Semi Invasive and Non Invasive Techniques: A Prospective Studying Postoperative Off Pump Coronary Artery Bypass Surgery Patients. Journal of Clinical Monitoring and Computing, 23, 175-180. http://dx.doi.org/10.1007/s10877-009-9179-7

[26] Summers, R.L., Shoemaker, W.C., Peacock, W.F., Ander, D.S. and Coleman, T.G. (2003) Bench to Bedside: Electrophysiologic and Clinical Principles of Noninvasive Hemodynamic Monitoring Using Impedance Cardiography. Academic Emergency Medicine, 10, 669-680. http://dx.doi.org/10.1111/j.1553-2712.2003.tb00054.x

[27] Zoremba, N., Bickenbach, J., Krauss, B., Rossaint, R., Kuhlen, R. and Schalte, G. (2007) Comparison of Electrical Velocimetry and Thermodilution Techniques for the Measurement of Cardiac output. Acta Anaesthesiologica Scandinavica, 51, 1314-1319. http://dx.doi.org/10.1111/J.1399-6576.2007.01445.X

[28] Van der Meer, B.J., de Vries, J.P., Schreuder, W.O., Bulder, E.R. and Eysman, L. (1997) Impedance Cardiography in Cardiac Surgery. Abnormal Body Weight Gives Unreliable Cardiac Output Measurements. Acta Anaesthesiologica Scandinavica, 41, 708-712. http://dx.doi.org/10.1111/j.1399-6576.1997.tb04770.x

[29] Kaukinen, S., Koobi, T., Bi, Y.B. and Turjanmaa, V.M.H. (2003) Cardiac Output Measurement after Coronary Artery Bypass Grafting Using Bolus Thermodilution, Continuous Thermodilution and Whole Body Impedance Cardiography. Journal of Cardiothoracic and Vascular Anesthesia, 17, 199-203. http://dx.doi.org/10.1053/jcan.2003.47

[30] Noonan, P.M., Vishwanathan, S., Chambers, A. and Stumper, O. (2013) Non-Invasive Cardiac Output Monitoring during Catheter Interventions in Patients with Cavopulmonary Circulations. Cardiology in the Young, 17, 1-5. 
Scientific Research Publishing (SCIRP) is one of the largest Open Access journal publishers. It is currently publishing more than 200 open access, online, peer-reviewed journals covering a wide range of academic disciplines. SCIRP serves the worldwide academic communities and contributes to the progress and application of science with its publication.

Other selected journals from SCIRP are listed as below. Submit your manuscript to us via either submit@scirp.org or Online Submission Portal.
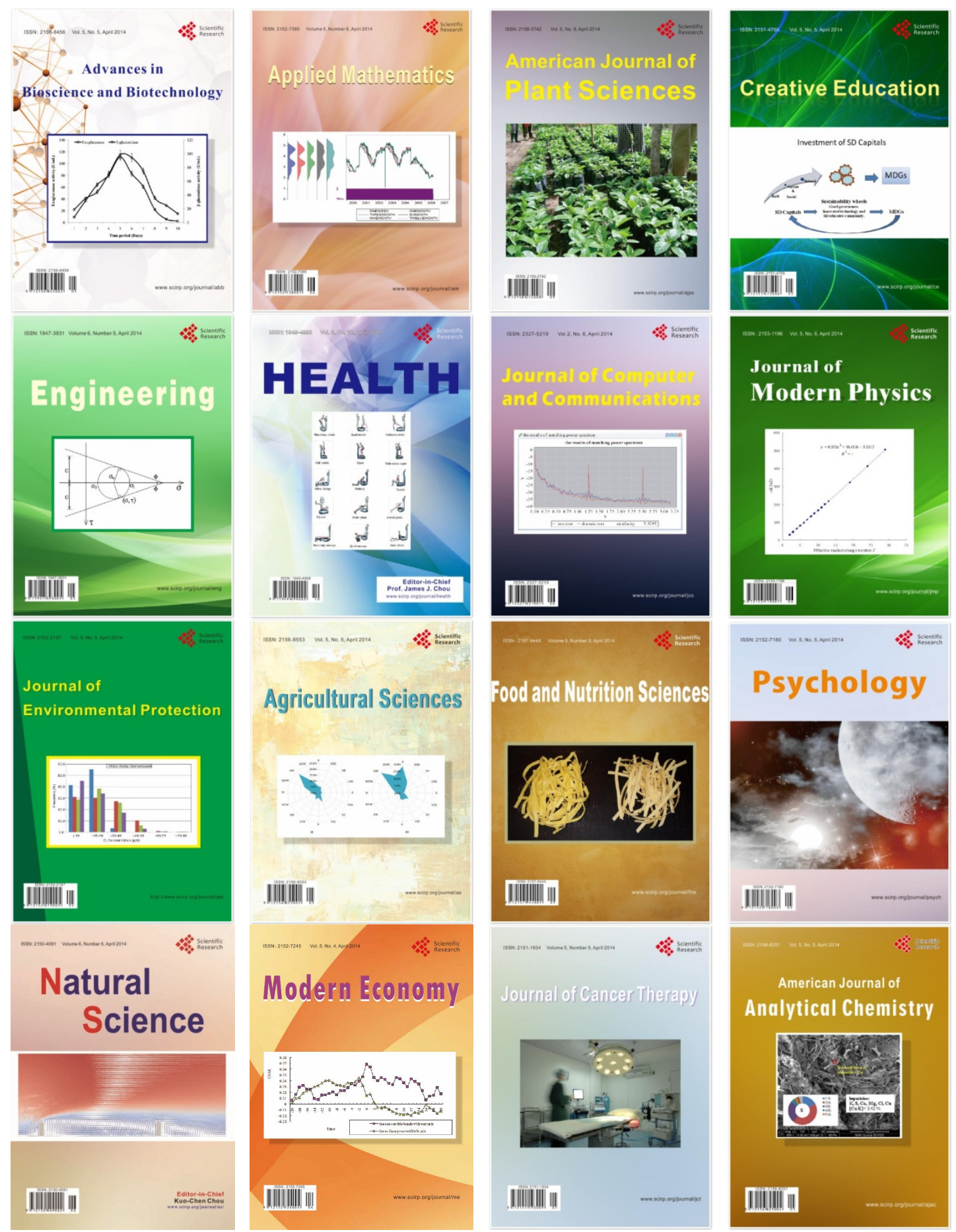